\title{
Effect of Single Axis Solar Tracking System on the Performance of Photovoltaic System: A Comparative Experimental Study
}

\section{Ravindra Pratap Singh}

Department of Mechanical Engineering, GLA University, Mathura, U P- India. pratap.ravindra@gla.ac.in

Article History: Received: 10 November 2020; Revised: 12 January 2021; Accepted: 27 January 2021; Published online: 05 April 2021

\begin{abstract}
Nowadays the demand for energy increased rapidly duo to escalating population and global technological development. Consequently, the focus on non-conventional energy sources is increasing rapidly due to change in climates and unhealthy environment caused by fossil fuels. Solar energy is vital to fulfill this growing need of clean energy. The performance of the photovoltaic (PV) technology used for capturing sun's radiation is directly affected by solar irradiation. The optimum performance of the PV systems would be possible if the solar panel is always orientated towards the direction of maximum radiations of sun. Hence, in order improve the performance of the PV, tracking of maximum radiation of the sun is extremely important. In this experimental study, solar tracking is done using a single axis solar sun tracker which not only provides accurate but also cost efficient solar sun tracking in comparison with an existing stationary system of same capacity. The results show that a single axis solar tracking systems have generated approximately $28.3 \%$ more compared to static systems and is also found to be more economic than a solar tracking system which uses microcontroller.
\end{abstract}

Keywords: Azimuth angle, Photovoltaic system, Single axis tracking, Solar energy, Optimum performance

\section{Introduction}

The day by day increase in energy demand with the development in technology and emission of harmful gases $(\mathrm{CO} 2, \mathrm{CO})$ by the use of fossil fuels, are the reasons responsible for encouraging the use of sustainable renewable energy resources. Solar energy is considered as clean and sustainable source of renewable energy. Photovoltaic systems are commonly used for converting sustainable and clean solar energy into electrical energy. This energy conversion efficiency of PV system is about $20 \%$ Lui et al. [1]. The energy produced by the solar photovoltaic system depends on the sun radiation falling on the photovoltaic panel. The Sun tracking system position the PV panel in the direction of sun radiation to receives maximum radiation. Therefore, the tracking of solar radiation can improve the efficiency of a solar photovoltaic system.

We can enhance efficiency of the solar PV system by using some mechanism and making bit effective by using single axis tracking system and dual axis tracking system. Anush et al. [2] performed comparison study between single axis tracking system and fixed PV panel system and reported around $40 \%$ increase in efficiency and received solar energy. Dhanabal et al [3] obtained a gain of $32.17 \%$ and $81.68 \%$ in solar energy with single axis and dual axis solar tracker, respectively. Hon and Kolte. [4] used solar tracking system based on field programmable gate array sensor, stepper motor and reported more efficiency than static panel. Boine et al. [5] used concentrated PVs with tracking, the PV with fixed and tracking system to pumping system. The shows that pumping system pumped 12.6, 4.9 and $7.4 \mathrm{~m} 3$ /day with concentration PVs-tracking, fixed and tracking PV respectively. Suri et al. [6] studied the energy output produced form vertical single axis tracker inclined vertically 30o north and fixed flat PV systems. The results shown that energy received with single tracking was improvised by $35 \%$ compared to fixed panel PV at optimum tilt Drury et al. [7]; Kumar and Sharma [8] used horizontal single axis system and observed increase in the efficiency up to $25 \%$ as compared to static system with $25 \mathrm{degree}$ tilt facing south. It was also observed that system efficiency could increased by $30 \%$ with dual axis system. Shugar and Hickmen[13] observe that dual axis solar tracker is $9 \%$ more effective than single axis tracker. Bakos[14] design panel $46 \%$ more efficiency than fixed one. Alata et al. [15] use logical algorithm for making dual axis tracker, used complex equation and collect the important data from GPS and other stuffs. Bingol et al. [16]; Singh and Sharma[17] made dual axis solar tracker by using LDR sensor, servomotor and microcontroller. The ability to use graphene instead is making possible truly flexible, low-cost, transparent PV solar cells that can turn virtually any surface into a source of electric power. 


\subsection{Solar system}

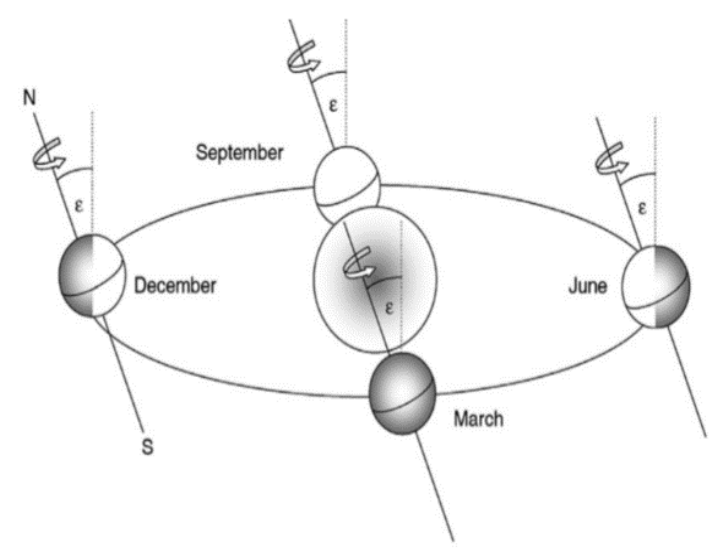

Figure 1. Earth orbit around sun. Sproul et al.[9].

The orbit of earth about sun is on an average distance of 149.6 million Km. Tilt angle of earth is $\varepsilon=23.441^{\circ}$ with respect to normal to the plane of earth's orbit [8] as shown in figure.1. The tilt angle of earth is same but the altitude of the sun is varying in year. The angle between the horizontal axis and the solar photovoltaic panel as illustrated in figure.2. The angle of incidence is a form of tilt angle, Hafeez and Soliman [10]. The azimuth angle and the altitude angle are used to specify the position of sun in the sky as illustrated in figure.3. The value of altitude angle is ranges between 0 degree and 180 degree for sunrise to sunset. The angle measured clockwise from north to the point on the horizon directly below the sun is called azimuth angle.

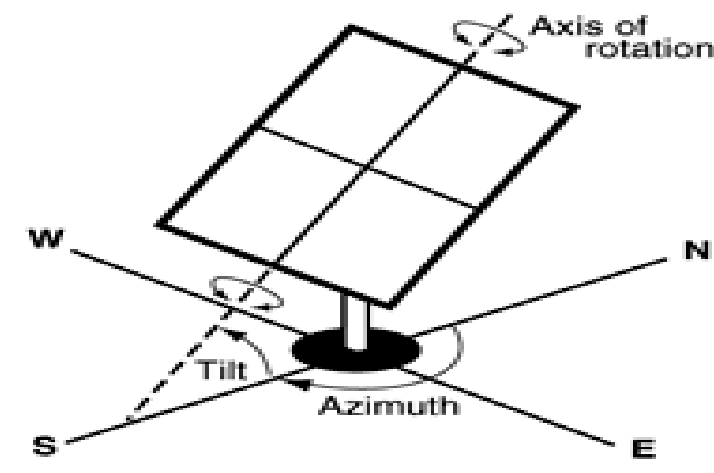

\section{One axis tracking PV array}

with axis oriented south.

Figure 2. Tilt angle. Tudorache et al. [11]

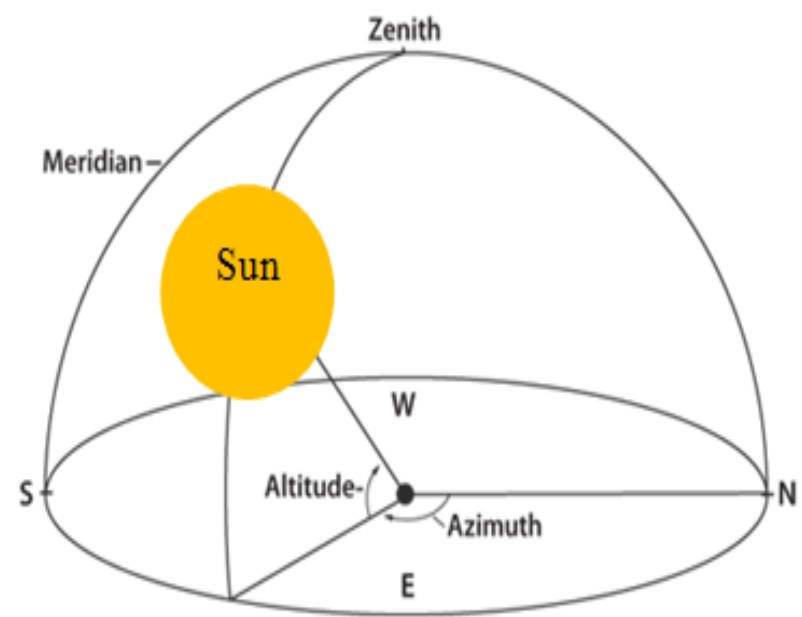

Figure 3. Altitude and azimuth angle. Sidek et al.[12] 


\section{Experimentation}

The circuit used in experimental setup consists of integrated circuit (IC), capacitor, relays, resistances, LDR, photo sensing device, etc connected at zero degree with the panel so that only the maximum sun radiation should received on the panel. The silicon mono-crystalline solar panel $(85 \mathrm{~W}, 20 \mathrm{~V})$ was used to harvest the solar energy.

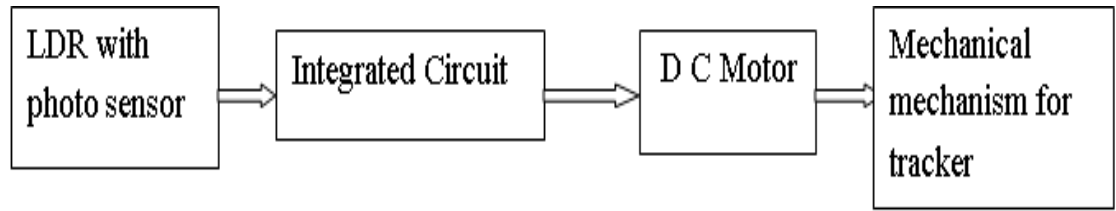

Figure 4. Block diagram of experimental set up

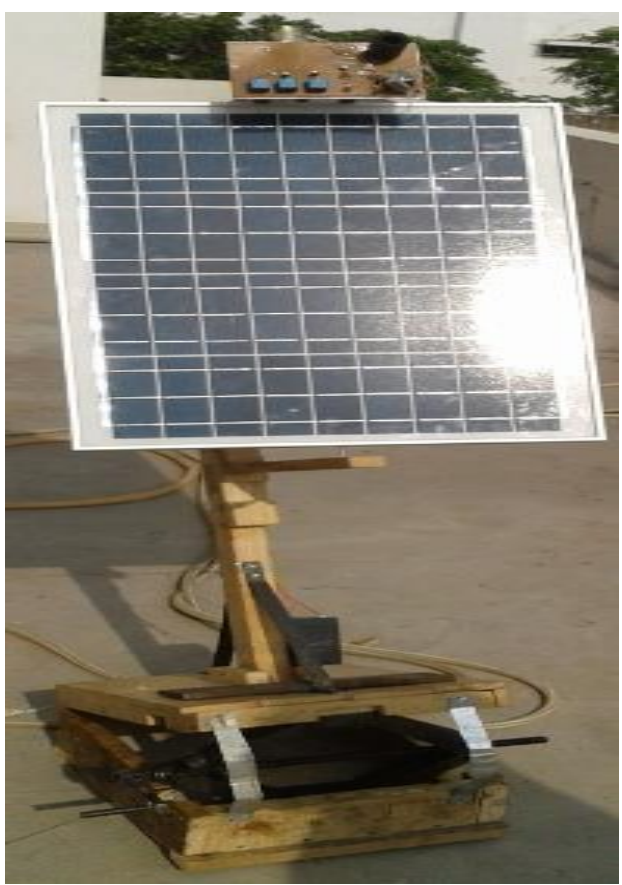

Figure 5. Experimental setup

LDR have a low resistance during the day and when voltage is passed through it, the drop in the voltage is not so large i.e. this sample voltage is greater than the reference voltage and so the relays will not be operated by the transistor (n-p-n) which is a switch. LDR have a very high resistance less light fall during evening and when voltage is passed through it, the drop in the voltage is such that this sample voltage is less than the reference voltage. the solar panel must be set to the initial position for the tracking. When IC compares that the sample voltage is less than the reference voltage it is signaled to the transistor so that transistor operates the relays. The relays changes the polarity of the DC Geared motor and the panel will be set to the initial position. As the panel reaches the initial position, the panel strikes the tripper and the circuit will break so that the panel becomes stationary at the initial position and the motor does not draw any power from the battery.

Table 1. Power generation for both static and tracking system.

\begin{tabular}{|l|l|l|l|}
\hline S. No. & Time & $\begin{array}{l}\text { Fixed PV system } \\
\text { Power(Watt) }\end{array}$ & $\begin{array}{l}\text { Single axis tracker } \\
\text { Power(Watt) }\end{array}$ \\
\hline 1. & $8: 00$ & 0.237 & 0.241 \\
\hline 2. & $9: 00$ & 0.238 & 0.243 \\
\hline 3. & $10: 00$ & 0.228 & 0.239 \\
\hline 4. & $11: 00$ & 0.209 & 0.240 \\
\hline 5. & $12: 00$ & 0.188 & 0.239 \\
\hline 6. & $13: 00$ & 0.164 & 0.232 \\
\hline
\end{tabular}


Effect of Single Axis Solar Tracking System on the Perfomance of Photovoltaic System: A Comparative Experimental Study

\begin{tabular}{|l|l|l|l|}
\hline 7. & $14: 00$ & 0.136 & 0.225 \\
\hline 8. & $15: 00$ & 0.115 & 0.222 \\
\hline 9. & $16: 00$ & 0.080 & 0.218 \\
\hline 10. & $17: 00$ & 0.063 & 0.214 \\
\hline 11. & $18: 00$ & 0.059 & 0.211 \\
\hline
\end{tabular}

\section{Result and Discussion}

The system was tested from 8.00 A.M to 6.00PM. It can be observe form the figure 6 and 7 that in the early hours before the 12.00 noon, the voltages and currents generated by the static panel are not significantly low compare to single axis tracker. However, after 2.00 PM there is a significant drop in voltages and current generated by fixed panel due large deviation from maximum sun radiation receiving position.

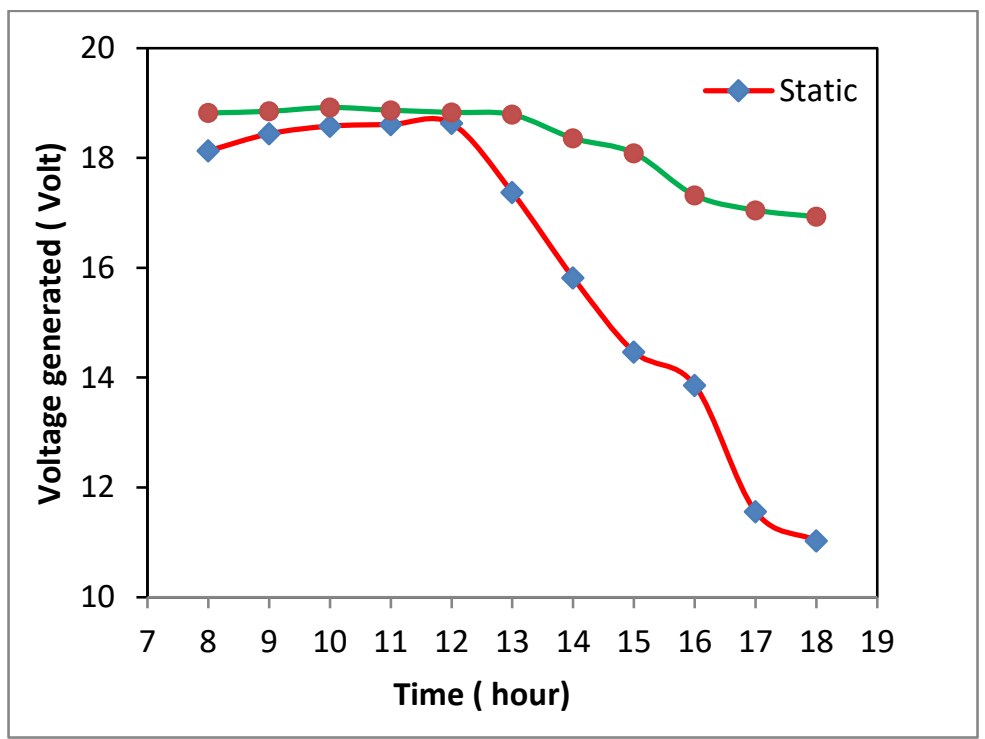

Figure 6. Voltage generated with time

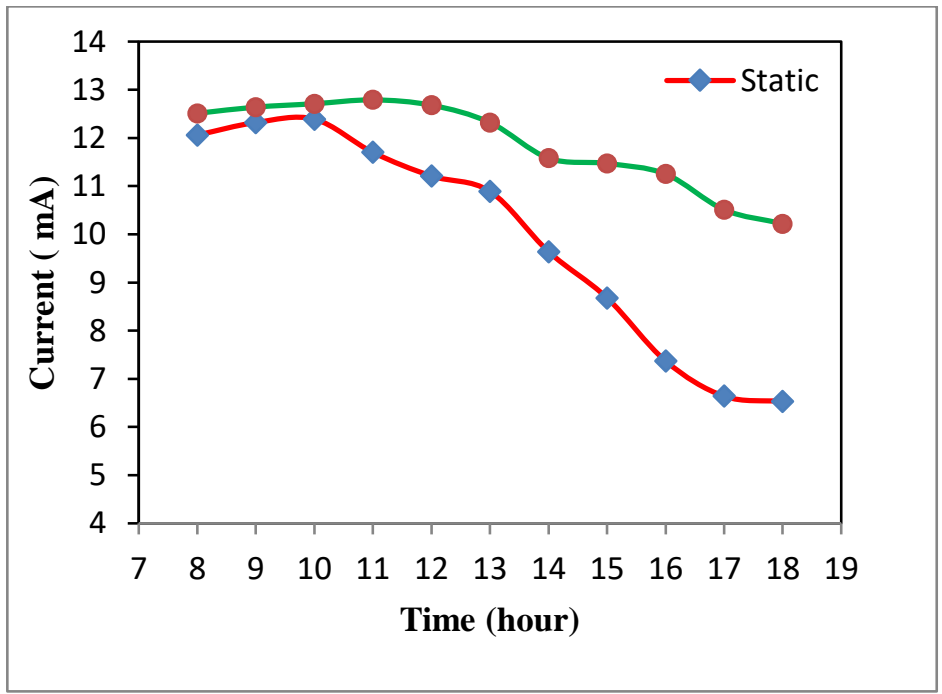

Figure 7. Variation of Current with time 


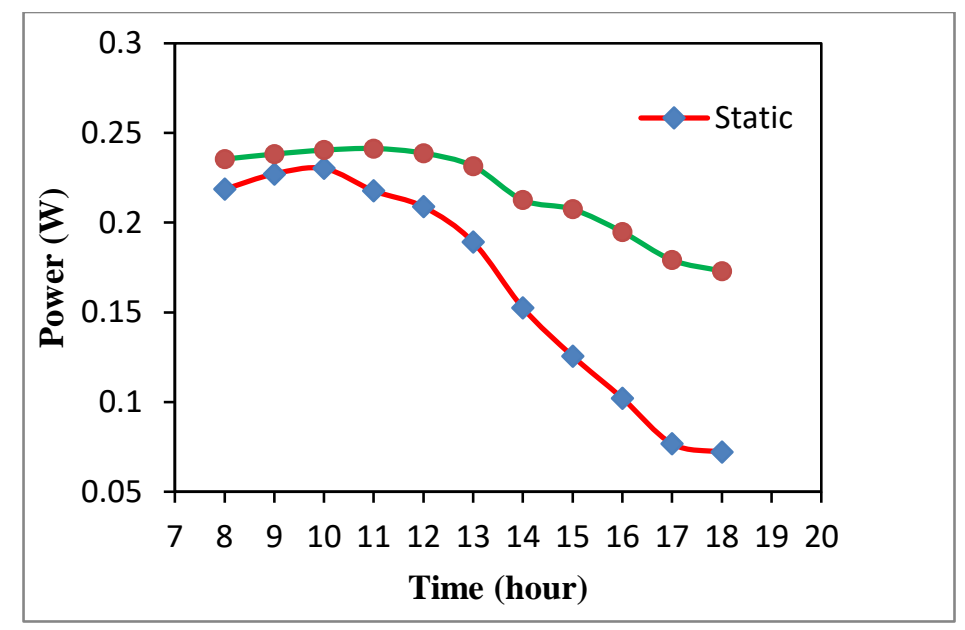

Figure 8. Power generated with time the PV system.

It can observe from figure. 8 that single axis tracking system improves the average power generated by

\section{Conclusion}

The fixed system generates less power due fixed orientation so a single axis solar tracing system can be used to absorb more solar energy compared to static or fixed system. However, the power consumed by electronic circuit may reduce this gain in power generation. In this study net average gain of approximately $28.3 \%$ in power generated observed after considering the power consumed by electric circuit.

\section{References}

1. Liu, L., Meng, X., \& Liu, C., "A review of maximum power point tracking methods of PV power system at uniform and partial shading", Renewable and Sustainable Energy Reviews, Vol.53, pp.1500-1507,2016.

2. Anusha, K., S. Chandra, and Mohan Reddy, "Design and Development of Real Time Clock Based Efficient Solar Tracking System", International Journal of Engineering Research and Applications(IJERA), Vol.3, no.3, pp. 1219-1223, 2013.

3. Dhanabal, R., Bharathi, V., Ranjitha, R., Ponni, A., Deepthi, S., \& Mageshkannan, P. "Comparison of efficiencies of solar tracker systems with static panel single-axis tracking system and dual-axis tracking system with fixed mount", International journal of engineering and technology, Vol.5 no.2, pp.1925-1933, 2013.

4. Hon, S. P., \& Kolte, M. T., "FPGA Based Standalone Solar Tracking System", International Journal of Scientific and Research Publications, Vol.3, no.10, pp.1-5, 2013.

5. Bione, J., O. C. Vilela, and N. Fraidenraich., "Comparison of the Performance of PV Water Pumping Systems Driven by Fixed, Tracking and V-trough Generators", Solar Energy, Vol.76, no.2, pp.703-711, 2004.

6. Suri, M., Cebecauer, T., Skoczek, A., \& Betak, J., "Solar electricity production from fixedinclined and sun-tracking c-Si photovoltaic modules in South Africa. In 1st Southern African Solar Energy Conference (SASEC), pp. 21-23, 2012.

7. Drury, E., Lopez, A., Denholm, P., \& Margolis, R., "Relative performance of tracking versus fixed tilt photovoltaic systems in the USA. Progress in Photovoltaics", Research and Applications, Vol.22, no.12, pp. 1302-1315, 2014.

8. A Kumar, K Sharma, AR Dixit, "A review of the mechanical and thermal properties of graphene and its hybrid polymer nanocomposites for structural applications", Journal of materials science, Vol.54, no.8, pp.5992-6026, 2019.

9. Sproul, A. B.,"Derivation of the solar geometric relationships using vector analysis", Renewable energy, Vol.32, no.7, pp.1187-1205, 2007.

10. Hafez, A. Z., Soliman, A., El-Metwally, K. A., \& Ismail, I. M., "Tilt and azimuth angles in solar energy applications-A review", Renewable and Sustainable Energy Reviews, Vol.77, pp147-168, 2017. 
11. Tudorache, T., Oancea, C. D., \& Kreindler, L., "Performance evaluation of a solar tracking PV panel. University", Politehnica of Bucharest Scientific Bulletin, Series C: Electrical Engineering, Vol. 74, no.1, pp. 3-10, 2012.

12. Sidek, M. H. M., Hasan, W. Z. W., Kadir, M. A., Shafie, S., Radzi, M. A. M., Ahmad, S. A., \& Marhaban, M. H. "GPS based portable dual-axis solar tracking system using astronomical equation”, IEEE International Conference on Power and Energy (PECon), pp. 245-249, 2014.

13. Shugar, D. S., Hickman, T., Eckert, P., \& Lepley, T., "Commercialization of a value-engineered photovoltaic tracking system", In Conference Record of the Twenty Fifth IEEE Photovoltaic Specialists Conference, pp. 1537-1540, 1996.

14. Bakos, G. C., "Design and construction of a two-axis Sun tracking system for parabolic trough collector (PTC) efficiency improvement", Renewable energy, Vol. 31, no.15, pp. 2411-2421, 2006.

15. Alata, M., Al-Nimr, M. A., \& Qaroush, Y., "Developing a multipurpose sun tracking system using fuzzy control", Energy Conversion and Management, Vol.46, no.7-8,pp. 1229-1245.

16. O. Bingol, A. Altintaş, Y. Oner., "Microcontroller Based Solar-Tracking System and its Implementation", Journal of Engineering Science, Vol.12, no.2, pp. 243-248, 2006.

17. Singh, R., K. Sharma, and A. Tiwari., "An Experimental Investigation of Thermal Conductivity of TiO2 Nanofluid: Proposing a New Correlation”, Journal of Scientific Industrial Research, Vol. 78, pp.620-623, 2019 